See Article page 1.

\section{Commentary: Quadricuspid aortic valve - the anatomic four-leaf clover}

\author{
John Bozinovski, MD, MSc
}

Four-leaf clovers are rare; about one in ten thousand according to the Better Homes and Gardens website. ${ }^{1}$ The leaves are said to represent faith, hope, caring, and success. We commonly embark upon surgery with these sentiments. Like the clover, the aortic valve usually has 3 "leaves" and rarely 4 , often of unequal size. In these ways, the quadricuspid aortic valve is anatomically analogous to the 4-leaf clover.

When encountering rare pathology, especially one inducing symptoms, one of the first questions that comes to mind is whether anyone else has previously encountered it and how did they address the problem. Often, we use techniques that are applied to similar pathology but tailored to the needs at hand. Our colleagues from Saint Luc University Clinics in Belgium describe their approach to a pseudoquadricuspid aortic valve. ${ }^{2}$ The "pseudo" qualifying term was used because it did not nicely meet the criteria for a quadricuspid valve, namely 4 distinct cusps separated by 4 distinct commissures. In this particular case, the bifid morphology of the noncoronary cusp would have made this a quadricuspid valve were it not for the fusion of the left and right cusps. Physically, this was a tricuspid valve with 3 cusps and 1 median raphe. This in itself is a unique class of defect combining a less-common bicuspid deformity with a rare bifid deformity. The authors represent a center in which the volume of aortic and aortic valve interventions is large, and they recall never before encountering this pathology, attesting to the scarcity of the anatomic variant.

\footnotetext{
From the Division of Cardiac Surgery, The Ohio State University Wexner Medical Center, Columbus, Ohio.

Disclosures: The author reported no conflicts of interest.

The Journal policy requires editors and reviewers to disclose conflicts of interest and to decline handling or reviewing manuscripts for which they may have a conflict of interest. The editors and reviewers of this article have no conflicts of interest.

Received for publication Sept 20, 2021; revisions received Sept 20, 2021; accepted for publication Sept 24, 2021; available ahead of print Sept 28, 2021.

Address for reprints: John Bozinovski, MD, MSc, N816A Doan Hall, 410 West 10th Ave, Columbus, OH 43210 (E-mail: jovan.bozinovski@ osumc.edu).

JTCVS Techniques 2022;11:5-6

2666-2507

Copyright (C) 2021 The Author(s). Published by Elsevier Inc. on behalf of The American Association for Thoracic Surgery. This is an open access article under the CC BY-NC-ND license (http://creativecommons.org/licenses/by-nc-nd/4.0/).

https://doi.org/10.1016/j.xjtc.2021.09.041
}

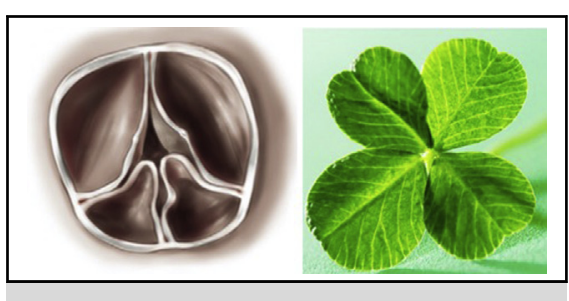

Quadricuspid aortic valve and quadri-leaflet clover.

\author{
CENTRAL MESSAGE \\ The quadricuspid aortic valve has \\ similarities to the 4 -leaf clover. \\ The clover's leaves represent \\ hope, faith, caring, and success. \\ Durability would be a nice \\ addition
}

The authors describe a repair of the valve incorporating various techniques including shaving the median raphe and aortic cusps of fibrous thickening, subcommissural annuloplasty, and supra-sinus stabilization with an appropriately sized ascending aortic graft. The video also shows mobilization of a partially fused commissure. There are valuable directions in the report for surgeons looking to embark upon, or further hone, aortic valve repairs in general. The good result of the repair is commendable and provides confirmation of the feasibility of repair. While feasibility of repair is an important consideration, it is not the only benchmark to be considered. Durability of the repair also needs to be given attention. We have found elsewhere, even when valve repairs have resulted in an immediately well-functioning valve, durability of the repair provided concern. ${ }^{3,4}$

Looking at aortic valve repairs in particular, Guo and colleagues ${ }^{4}$ found there were features that portend to lesser durability of valve competence including, but not limited to, preoperative indexed left ventricular end systolic diameter greater than $2.0 \mathrm{~cm} / \mathrm{m}^{2}$ and immediate residual aortic valve insufficiency of any degree. Thus, we are left optimistic that, even in the face of rare defects, valve preservation is a worthwhile pursuit while remaining cautious to assess the durability of the repairs. The patient in the report underwent surgery recently, and only near-term follow-up has been completed. However, faith, hope, care, and luck, along with dexterous hands, provide an opportunity to avoid valve prostheses and to maximize patient benefit. 


\section{References}

1. VanSchmus E. 7 Fun Facts About Four-Leaf Clovers to Get in the St. Patrick's Day Spirit. Better Homes and Gardens. Available at: https://bhg.com/holidays/stpatricks-day/traditions/fun-facts-about-four-leaf-clovers/. Accessed September, 2021.

2. Klepper M, Jahanyar J, Aphram G, de Kerchove L, El Khoury G. A rare case of pseudo-quadricuspid aortic valve repair. J Thorac Cardiovasc Surg Tech. 2022; $11: 1-4$.
3. Goldstein D, Moskowitz AJ, Gelijns AC, Ailawadi G, Parides MK, Perrault LP, et al. Two-year outcomes of surgical management of severe ischemic mitral regurgitation. N Engl J Med. 2016;374:344-53.

4. Guo MH, Cole E, Fei LYN, Mussani J, Tran D, Glineur D, et al. Preoperative left ventricular end-systolic dimension predicts occurrence of aortic insufficiency following aortic valve-preservation and repair surgery. $J$ Thorac Cardiovasc Surg. December 3, 2020; https://doi.org/10.1016/j.jtcvs.2020.10.159 [Epub ahead of print]. 